Analy tica Chimica Acta, 109 (1979) 145-148

(-) Elsevier Scientific Publishing Company, Amsterdam - Printed in The Netherlands

Short Communication

\title{
THE ION-SENSITIVE FIELD EFFECT TRANSISTOR IN RAPID ACID- BASE TITRATIONS
}

\author{
M. BOS*, P. BERGVELD and A. M. W. VAN VEEN-BL.AAUW
}

Department of Chemical Technology. Twente University of Technology. Enschede (The Netherlands)

(Received 12th March 1979)

Summary. Ion-sensitive field effect transistors (ISFETs) are used as the pH sensor in rapid acid-base titrations. Titration speeds at least five times greater than those with glass electrodes are possible for accuracies better than $\pm 1 \%$.

The speed of automated acid-base titrations is normally limited by the slow response of the glass electrode [1]. Computer control of the titrant delivery in titrations to preset end-points [2], as well as in equilibrium titrations [3], improves the situation but results better than $\pm 1 \%$ still require titration times of the order of $4 \mathrm{~min}$ [4].

Field effect transistors can be used as $\mathrm{pH}$ sensors by replacing the gate metal with silicon nitride or polymeric $\mathrm{pH}$-selective membranes [5]. The silicon dioxide of the transistor structure itself, that normally insulates the gate metal, also exhibits $\mathrm{pH}$ sensitivity [6]. In contrast to the glass electrode, ISFETs do not need high-impedance metering circuits, hence the long time constants caused by cable capacity and high internal resistance of glass electrodes are absent [7]. Accordingly, the use of ISFETs to monitor acid-base titrations should allow considerably higher speeds in these titrations. Moreover, the size of the ISFET, mounted as a probe, is only a few $\mathrm{mm}^{2}$, so that if a small enough reference electrode were available, it would be possible to monitor titrations on the microliter scale.

This work was undertaken to study the possibility of rapid acid-base titrations with the aid of an ISFET with the silicon dioxide of its gate area used as the pH-sensitive layer. This use of the dioxide of the transistor itself was preferred, as a shorter response time was expected with this device than with the membrane-covered types of $\mathrm{pH}$-sensitive ISFETs.

\section{Experimental}

Chemicals. Potassium chloride (Merck, reagent grade) and tris(hydroxymethyl)aminomethane (Tris, Fluka, puriss) were used as received. Standard solutions of hydrochloric acid, sodium hydroxide and acetic acid (all in $1 \mathrm{M}$ $\mathrm{KCl}$ ) were prepared from Merck Titrisol ampoules by adding the calculated amount of potassium chloride to a 1-1 volumetric flask together with the 
content of the ampoules and filling to the mark with twice-distilled $\mathrm{CO}_{2}$ free water.

The ISFET and its amplification system. The ISFET configuration was similar to that described by Matsuo and Wise [7] and was mounted on a ceramic support $(1.6 \mathrm{~mm}$ by $50 \mathrm{~mm})$. Source, drain and bulk connections were wire-bonded with fine gold wires to three conducting silver palladium pads, which were deposited on the ceramic support by means of thick-film technology and soldered at the distal end to a small connector. The whole probe was insulated, except for the gate area, with three layers of diluted silicone rubber. The $500 \AA$ thermal dioxide of the gate was protected during mounting and storage by evaporated aluminium, which was removed (see below) just before the measurement.

The ISFET was connected to a specially developed ISFET amplifier [8], which supplies a constant drain-to-source voltage of $100 \mathrm{mV}$, while the source and drain potential, having a mean value of $1 \mathrm{~V}$ with respect to earth, follows the gate potential because of feedback (bootstrapping). The bulk was connected to earth as well as to the reference electrode in the liquid. This system is capable of transferring very high frequencies, because the capacitances between the liquid and the source and drain, as well as between the source and drain potential, having a mean value of $\mathrm{I} \mathrm{V}$ with respect to earth, connected to low impedances, preventing interference from ambient electrical fields. The output voltage of the ISFET amplifier can be simply calibrated in pH units, independent of ISFET characteristics, because of the feedback principle.

Titration equipment. A schematic diagram of the titration equipment is shown in Fig. 1. A recorder (Kipp, type BD8) connected to the ISFET amplifier registers $\mathrm{pH}$ versus time. The motor burette (Mettler, type DV11) is operated at constant speed, so that the time-axis of the chart can be calibrated in volume units. This is done by generating markers on the recorder paper with the switch that also starts and stops the burette. The ref-

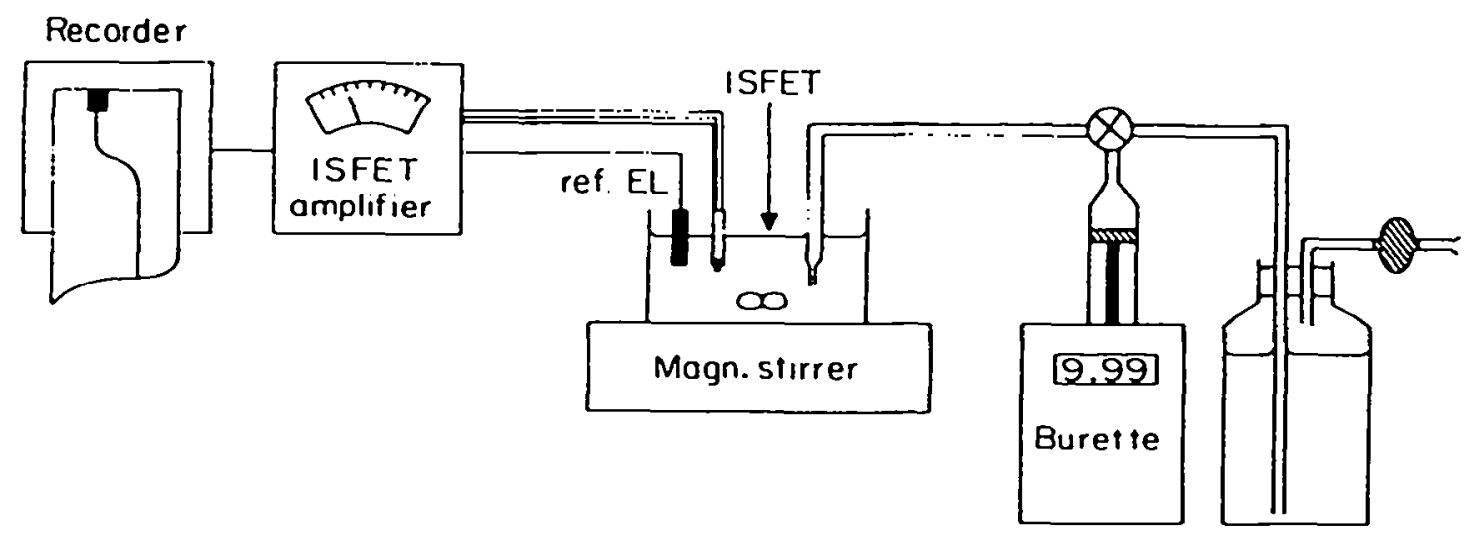

Fig. 1. Schematic diagram of titration equipment with ISFET. 
erence electrode used in conjunction with the ISFET is a silver/silver chloride electrode (Ingold, ty pe 363-NS-M5). The magnetic stirrer runs at about $450 \mathrm{rpm}$ with a $21 \times 5-\mathrm{mm}$ Teflon bar in a titration beaker (3.4-cm inner diameter).

Procedures. Before the ISFET is used, its aluminium gate metal is removed from the underlying silicon dioxide by etching the ISFET for about $10 \mathrm{~min}$ at $50^{\circ} \mathrm{C}$ with a drop of a solution of $75 \%$ phosphoric acid, $10 \%$ acetic acid, $5 \%$ nitric acid and $15 \%$ water. During this treatment the silicon dioxide becomes hydrated and pH-sensitive. When not in use the ISFET is stored dry after rinsing with distilled water.

Titrations of bases were carried out under a nitrogen blanket. For comparison purposes, all titrations were also performed with the use of a combined glass electrode, the $1 \%$ errors obtained only for titrant addition rates of $0.9 \mathrm{ml} \mathrm{min}^{-1}$ or less. That the titration speed is not limited by the ISFET were done in $1 \mathrm{M}$ potassium chloride solutions so that activity coefficients, theoretical titration curves and the $\mathrm{pH}$ values of equivalence points could be calculated easily. In all cases the starting volume in the titration vessel was $20.0 \mathrm{ml}$.

\section{Results}

Figure 2A shows a comparison between the performance of the glass electrode and the ISFET in the titration of samples of $0.500 \mathrm{mmol}$ Tris with $0.1000 \mathrm{M}$ hydrochloric acid at various speeds. The rate of addition of titrant varied between 5.0 and $0.17 \mathrm{ml} \mathrm{min}^{-1}$. The results given are mean values and the standard deviations for the results obtained at one titration speed were below $\pm 0.2 \%$. It can be seen that, even at the highest titration speed of $5.0 \mathrm{ml} \mathrm{min}^{-1}$, the ISFET produces titration errors smaller than 1\%. For the glass electrode, the $1 \%$ errors obtained only for titrant addition rates of $0.9 \mathrm{ml} \mathrm{min}-1$ or less. That the titration speed is not limited by the ISFET response can be seen from Fig. $2 A$, where the lowest trace corresponds to the results for some titrations in a smaller vessel in which mixing was promoted by two glass strips on the wall causing better turbulence.

In the reverse titration, i.e. titrations of $0.500 \mathrm{mmol}$ of hydrochloric acid with $0.1000 \mathrm{M}$ Tris, the difference in performance between the glass electrode and the ISFET is less pronounced, but the results for the titrations with the ISFET are considerably better for all titration speeds (Fig. 2B). These error curves also show that both the ISFET and the glass electrode respond more slowly to changes from acid to alkaline pll values than to the reverse changes.

The response of the ISFET to $\mathrm{pHI}$ changes is not Nernstian over the entire $\mathrm{pH}$ range [6], so that it depends on the $\mathrm{pH}$ values of the respective equivalence points whether or not differential titrations of mixtures can be successful. The differential titration of a mixture of $0.450 \mathrm{meq}$ of hydrochloric acid and 0.450 meq of acetic acid is possible with the use of a glass electrode (Table 1 ), but the accuracy is better than $1 \%$ only at titration speeds below $0.50 \mathrm{ml} \mathrm{min}-1$. If an ISFET is used as pH sensor, only one inflection point is observed in the titration curve; this end-point corresponds to the 

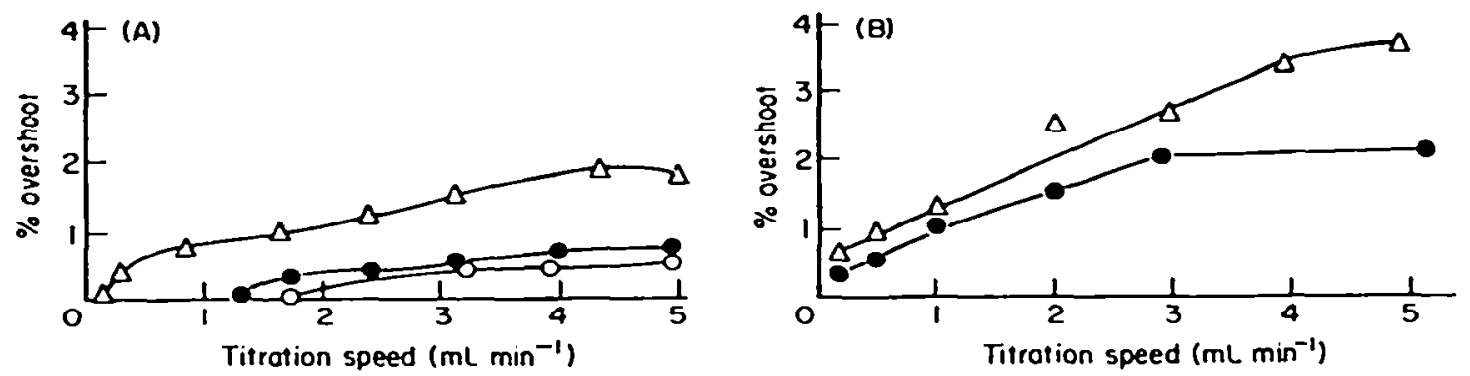

Fig. 2. Overshoot in the titration of (A) $0 . \overline{\mathrm{mmol}}$ Tris with $0.1000 \mathrm{M}$ hydrochloric acid, and (B) $0.5 \mathrm{mmol}$ hydrochloric acid with $0.1000 \mathrm{M}$ Tris. $(\Delta)$ Glass electrode; $(\bullet)$ ISFET: (०) ISFET with improved stirring.

\section{TABLE 1}

Overshoot in the titration of mixtures of 0.45 meq of hydrochloric acid and 0.45 meq of acetic acid by titration with $0.1000 \mathrm{M}$ sodium hydroxide

\begin{tabular}{|c|c|c|c|}
\hline \multirow[b]{2}{*}{$\begin{array}{l}\text { Titration } \\
\text { speed } \\
(\mathrm{ml} \min \rightarrow)\end{array}$} & \multicolumn{2}{|l|}{ Glass electrode } & \multirow{2}{*}{$\begin{array}{l}\text { ISFET } \\
\text { Overshoot for } \\
\text { end-pointa } \\
\text { (\%) }\end{array}$} \\
\hline & $\begin{array}{l}\text { Overshoot for } \\
\text { HCl end-point } \\
\text { (\%) }\end{array}$ & $\begin{array}{l}\text { Overshoot for } \\
\text { final end-point } \\
\text { (\%) }\end{array}$ & \\
\hline $\begin{array}{l}5.07 \\
2.94 \\
0.98 \\
0.50 \\
0.20\end{array}$ & $\begin{array}{l}2.95 \\
2.45 \\
1.40 \\
1.19 \\
0.53\end{array}$ & $\begin{array}{r}2.04 \\
1.62 \\
0.81 \\
0.18 \\
-0.71\end{array}$ & 0.6 \\
\hline
\end{tabular}

a $\mathrm{HCl}$ end-point undetectable.

total amount of hydrochloric and acetic acid, and at the full speed of the burette $\left(5.0 \mathrm{ml} \mathrm{min}^{-1}\right)$ the accuracy is $0.6 \%$.

The authors thank Mr. A. J. Verloop for accurate construction of the ISFET probes, Ms. M. Muring for preparing the manuscript, and Prof. E. A. M. F. Dahmen for his interes $i$ in this work.

\section{REFERENCES}

1 G. H. B. Eelderink, H. B. Verbruggen, F. A. Jutte, W. J. van. Oort and B. Griepink, Fresenius Z. Anal. Chem., 280 (1976) 273.

2 W. E. Earle and K. S. Fletcher, Chem. Instrum., 7 (1976) 101.

3 D. J. Leggett, Anal. Chem., 50 (1978) 718.

4 T. W. Hunter, J. T. Sinnamon and G. M. Hieftje, Anal. Chem., 47 (1975) 497.

5 P. T. McBride, J. Janata, P. A. Comte, S. D. Moss and C. C. Johnson, Anal. Chim. Acta, $101(1978) 239$.

6 N. F. de Rooy. The ISFET in Electrochemistry, Thesis, Technical University Twente, 1978, p. 32.

7 T. Matsuo and K. P. Wise, IEEE Trans. Biomed. Eng. Vol. BME-21 No. 6 (1974) 485.

8 P. Bergueld, Med. Biol. Eng. \& Comp., in press. 